OPEN ACCESS

Edited by:

Manuel Delgado Baquerizo, University of Alicante, Spain

Reviewed by:

Shengen Liu,

University of Chinese Academy

of Sciences, China

Muhammad Saleem, Alabama State University,

United States

*Correspondence:

Yan Ma

myjaas@sina.com

Roshini Govinden

govindenr@ukzn.ac.za

Specialty section:

This article was submitted to Terrestrial Microbiology,

a section of the journal

Frontiers in Microbiology

Received: 28 February 2020 Accepted: 02 June 2020 Published: 08 July 2020

Citation:

Wang G, Ma Y, Chenia HY, Govinden R, Luo J and Ren G (2020) Biochar-Mediated Control of Phytophthora Blight of Pepper Is Closely Related to the Improvement of the Rhizosphere Fungal Community

Front. Microbiol. 11:1427. doi: 10.3389/fmicb.2020.01427

\section{Biochar-Mediated Control of Phytophthora Blight of Pepper Is Closely Related to the Improvement of the Rhizosphere Fungal Community}

\author{
Guangfei Wang ${ }^{1,2}$, Yan Ma ${ }^{1,2 *}$, Hafizah Yousuf Chenia ${ }^{3}$, Roshini Govinden ${ }^{3 *}$, Jia Luo ${ }^{1,2}$ \\ and Gaidi Ren ${ }^{1,2}$
}

${ }^{1}$ Institute of Agricultural Resources and Environments, Jiangsu Academy of Agricultural Sciences, Nanjing, China, ${ }^{2}$ Key Laboratory of Agro-Environment in Downstream of Yangtze Plain, Ministry of Agriculture and Rural Affairs, Nanjing, China, ${ }^{3}$ Discipline of Microbiology, School of Life Sciences, College of Agriculture, Engineering and Science, University of KwaZulu-Natal, Durban, South Africa

Biochar is a new eco-material with the potential to control soilborne diseases. This study explored the relationship between the rhizosphere fungal community and the suppression of Phytophthora blight of pepper in the context of time after biochar application. A pot experiment was conducted and rhizosphere soils were sampled to determine the biochar-induced soil chemical properties, fungal community composition, and abundance of biocontrol fungi. The biochar-enriched fungal strains were screened by the selective isolation method, and their control effects against Phytophthora blight of pepper were determined using a pot experiment. Biochar treatments effectively inhibited pathogen growth and controlled the disease, with biochar applied immediately before planting $(\mathrm{BCO})$ having greater effects than that applied 20 days before planting (BC20). Compared to the control, biochar-amended rhizosphere soils had a higher $\mathrm{pH}$, available nutrient content, and fungal richness and diversity. Moreover, biochar treatments significantly increased the abundance of potential biocontrol fungi. The proliferation in BCO was stronger as compared to that in BC20. Several strains belonging to Aspergillus, Chaetomium, and Trichoderma, which were enriched by biochar amendment, demonstrated effective control of Phytophthora blight of pepper. Canonical correspondence and Pearson's correlation analysis showed that a high content of soilavailable nutrients in biochar treatments was favorable to the proliferation of beneficial fungi, which was negatively correlated with both the abundance of Phytophthora capsici and disease severity. In conclusion, biochar-mediated improvement in the fungal community suppressed the Phytophthora blight of pepper. The biochar application time had a great impact on the control effect, possibly due to the short-term proliferative effect of the biochar on biocontrol fungi.

Keywords: biochar, application time, Phytophthora blight of pepper, soil chemical properties, fungal community, biocontrol fungi 


\section{INTRODUCTION}

Biochar, the solid by-product of biomass pyrolysis, features stable aromatic carbon structures, large surface areas, and high contents of certain nutrients and organic carbon (Sohi et al., 2010; Lehmann et al., 2011). In addition to sequestering carbon and reducing greenhouse gas emissions, biochar application can improve the soil $\mathrm{pH}$, moisture retention, physical structure, nutrient status, and biological properties, which in turn enhance plant growth and health under biotic and abiotic stress conditions (Sohi et al., 2010; Egamberdieva et al., 2016; Nair et al., 2017; Meng et al., 2019).

Recent studies have shown that biochar application can effectively control soilborne plant diseases caused by pathogenic fungi and bacteria, such as Fusarium oxysporum, Rhizoctonia solani, and Ralstonia solanacearum (Jaiswal et al., 2014, 2015; Elmer, 2016; Zhang et al., 2017; Gao et al., 2019; Chen et al., 2020). Our previous study first reported that the addition of biochar to soil resulted in a good control effect of Phytophthora blight of pepper, caused by the pathogenic oomycete Phytophthora capsici L. (Wang et al., 2017). However, the mechanisms remain unknown. Biochar-induced soil chemical properties are closely associated with the control of diseases caused by soilborne bacteria (Zhang et al., 2017; Gao et al., 2019; Chen et al., 2020), but whether it is conducive to the control of diseases caused by oomycetes needs to be explored.

Biochar has a high $\mathrm{C} / \mathrm{N}$ ratio and can provide a habitat that is conducive to colonization by fungal hyphae (Lehmann et al., 2011). In addition, many fungi can proliferate by degrading the organic components within biochar (Anyika et al., 2015). Therefore, biochar application is beneficial for soil fungal growth. This has been confirmed by a significant increase in fungal abundance and changes in fungal communities following biochar amendment (Bamminger et al., 2014; Yao et al., 2017; Zhang et al., 2019; Wu et al., 2020). In addition, several researchers observed the enrichment of potential biocontrol fungi, such as Trichoderma and Paecilomyces, in biochar-amended soil (Hu et al., 2014; Elmer, 2016; Zhang et al., 2019). Thus, we hypothesized that biochar-mediated improvement of the rhizosphere fungal community, especially the enrichment of biocontrol fungi, is closely related to the suppression of soilborne diseases. Until now, no in-depth studies have analyzed the association between biochar-mediated disease control and the fungal community. Jaiswal et al. (2017, 2018) determined the fungal and bacterial communities in response to biochar and established a relationship between the bacterial community and disease suppression, but did not establish a relationship between the fungal community and disease suppression.

There are many studies showing the influence of feedstock, pyrolysis temperature, and application dose of biochar on their disease control effects (Jaiswal et al., 2014, 2015; Lu et al., 2016; Wang et al., 2017; Chen et al., 2020), but not one focused on the biochar application time. The application of biochar just before planting may maximize the control effect because of the short-term effect of biochar on soil biological properties (Farrell et al., 2013; Jiang et al., 2016). However, application a few days before planting to form disease-suppressing soil microflora may help improve the control effect. Therefore, we speculate that the biochar application time has a significant influence on its control effect and that this is caused by the time-dependent influence of the biochar on the soil microbial community.

Our aims for this study were as follows: (i) to analyze whether the biochar-mediated control of Phytophthora blight of pepper is related to an improved fungal community; (ii) to study whether the response of soil chemical properties to biochar amendment contributes to the improvement of the rhizosphere fungal community and suppression of Phytophthora blight of pepper; and (iii) to explore the association between the biochar application time and the rhizosphere fungal community as well as disease suppression. Therefore, we investigated the function of biochar in shaping soil chemical properties, fungal community composition, abundance of biocontrol fungi, pathogen abundance, and disease severity under different application times. Moreover, the screening and verification of biocontrol agents were performed to ascertain the relationship between biochar-enriched biocontrol fungi and disease suppression by biochar. The results of our work are expected to provide a practical approach for the utilization of biochar to control soilborne diseases and provide theoretical support for the further enhancement of plant disease control with biochar application.

\section{MATERIALS AND METHODS}

\section{Soil and Biochar Preparation}

The experimental soil had a sandy loam texture. It was collected from the top $20-\mathrm{cm}$ layer in a pepper greenhouse in Huangma town, Jiangsu Province, China. The basic chemical characteristics of the soil were as follows: $\mathrm{pH}, 7.44$; electrical conductivity (EC), $1,879 \mu \mathrm{s} / \mathrm{cm}$; total N, $3.1 \mathrm{~g} / \mathrm{kg}$; total P, $2.0 \mathrm{~g} / \mathrm{kg}$; total K, $12.6 \mathrm{~g} / \mathrm{kg}$; and organic matter, $29.4 \mathrm{~g} / \mathrm{kg}$.

The biochar was made from corn stalk based on the methods of Xie et al. (2013) and was passed through a 40-mesh screen. The basic characteristics of the biochar were as follows: $\mathrm{pH}$, 9.73; EC, 5,763 $\mu \mathrm{s} / \mathrm{cm}$; total C, $490 \mathrm{~g} / \mathrm{kg}$; total $\mathrm{H}, 23 \mathrm{~g} / \mathrm{kg}$; total $\mathrm{O}, 146 \mathrm{~g} / \mathrm{kg}$; total $\mathrm{N}, 17.5 \mathrm{~g} / \mathrm{kg}$; ash, $324 \mathrm{~g} / \mathrm{kg}$; organic matter, $286 \mathrm{~g} / \mathrm{kg}$; available P, $2.2 \mathrm{~g} / \mathrm{kg}$; and available K, $24.7 \mathrm{~g} / \mathrm{kg}$.

\section{Pot Experiment}

Three treatments were established: (i) soil incubated for 20 days without biochar (CK); (ii) CK soil amended with biochar at a rate of $13.3 \mathrm{~g} / \mathrm{kg}$ just before planting (BC0); and (iii) $\mathrm{CK}$ soil amended with biochar at a rate of $13.3 \mathrm{~g} / \mathrm{kg} 20$ days before planting (BC20). Treatments were prepared in triplicate and incubated at ambient temperatures of $15-30^{\circ} \mathrm{C}$. The soil moisture content was maintained approx. 20\% during incubation. All of the treatments were mixed with a $P$. capsici zoospore suspension at a density of 100 zoospores per gram soil at the end of the incubation period. Each treatment was repeated three times, and each replicate had 20 pots $(12 \mathrm{~cm} \times 15 \mathrm{~cm}$, diameter $\times$ height $)$. Each pot contained $600 \mathrm{~g}$ of soil and one 5-week-old pepper plant. The pots were randomly arranged and incubated inside the greenhouse for 45 days, as mentioned above. 
The disease index was recorded every 15 days using a $0-4$ scale according to Wang et al. (2019). Disease index $=[\Sigma$ (number of infected plants of a specific scale $\times$ the specific scale $/(4 \times$ (total number of plants))] $\times 100 \%$.

\section{Sample Collection and DNA Extraction}

Before planting, the soil samples were harvested from all of the replicates. At 15, 30, and 45 days after planting, five plants were randomly dug out from each replicate and the rhizosphere soil was harvested. The soil samples were passed through a 10-mesh screen. One portion of each sample was air dried and then stored at $4^{\circ} \mathrm{C}$ for the later analysis of $\mathrm{pH}, \mathrm{EC}$, organic matter, available $\mathrm{P}$, and available $\mathrm{K}$; the other portion was stored at $-70^{\circ} \mathrm{C}$ and used for the later extraction of total DNA and the determination of nitrate N. In addition, the soil samples harvested at day 30 after planting were used for the screening of biochar-enriched biocontrol fungi and the determination of the fungal community composition. Soil total DNA was isolated using a FastDNA SPIN Kit (MP Biomedicals).

\section{Analysis of Soil Chemical Properties}

Soil $\mathrm{pH}$ and $\mathrm{EC}$ (soil/water $=1: 5, w / v$ ) were measured using a $\mathrm{pH}$ meter (Mettler-Toledo FE20, Mettler-Toledo Instrument Factory, Shanghai, China) and an EC meter (DDS307, Shanghai Jingke Instrument Factory, Shanghai, China), respectively. Organic matter, nitrate $\mathrm{N}$, available $\mathrm{P}$, and available $\mathrm{K}$ were assayed according to the methods of Wang et al. (2014).

\section{Quantitative PCR}

SYBR Premix Ex Taq (Tli RNaseH Plus) was used to amplify the fungi, Chaetomium globosum, P. capsici, and Trichoderma on a 7500 quantitative PCR instrument (Applied Biosystems, United States). The fungal 18S rRNA gene was quantified using the primer pair NS1-F/FungR (Wang et al., 2014). The number of C. globosum, P. capsici, and Trichoderma were determined with the genus-specific primer pairs SCCgQF/SCCgQR (Aggarwal et al., 2014), CAPFW/CAPRV1 (Wang et al., 2014), and uTf/uTr (Hagn et al., 2007), respectively. TaqMan quantitative PCR (qPCR) of Aspergillus and Penicillium was conducted using Premix Ex Taq (Probe qPCR), and the primers/probes for Aspergillus and Penicillium were Asp2/AspG/Probe137 (Goebes et al., 2007) and ITSPF/ITSPR/ProbePENP (Suanthie et al., 2009), respectively. The copy numbers of the target genes in total fungi and P. capsici were calculated based on a plasmid-generated standard curve. The standard curves for the calculation of C. globosum, Aspergillus, Penicillium, and Trichoderma were prepared with 10-fold serial dilutions of genomic DNA.

\section{Illumina MiSeq Sequencing and Analysis}

Thirty days after planting, rhizosphere soil DNAs were extracted and then subjected to Illumina MiSeq sequencing by Majorbio Co., Ltd. (Shanghai, China). The primers ITS1F (5'-CTT GGT CAT TTA GAG GAA GTA A-3') and ITS2R (5'-GCT GCG TTC TTC ATC GAT GC-3') were used for the PCR assay of the fungal internal transcribed spacer (ITS) region of the target ribosomal gene (Bokulich and Mills, 2013). The PCR products were sequenced using the MiSeq sequencing platform, and all sequences were clustered into operational taxonomic units (OTUs) at 97\% identity using UPARSE (Kõljalg et al., 2013). The fungal community was characterized in terms of the number of OTUs, Shannon index, coverage, and the richness estimators Chao1 and ACE (abundance-based coverage estimation) using the mothur software (Schloss et al., 2009). OTUs were classified using the UNITE ITS database (Kõljalg et al., 2013). Principal coordinate analysis (PCoA) based on the weighted UniFrac distances was performed to determine the differences in the fungal community composition. Canonical correspondence analysis (CCA) was performed to determine the relationships between the soil chemical properties and the fungal community composition.

\section{Screening and Assessment of Biochar-Enriched Biocontrol Fungi}

Rhizosphere soil samples for the $\mathrm{CK}$ and $\mathrm{BC} 0$ treatments at 30 days after planting were collected as described above. Ten grams of the soil sample was added to $90 \mathrm{ml} 0.85 \%$ saline solution and shaken for $30 \mathrm{~min}$ at $160 \mathrm{rpm}$. After performing 10 -fold dilutions, $100 \mu \mathrm{l}$ of the diluted suspensions $\left(10^{-2}\right.$ and $10^{-3}$ ) was plated on potato dextrose agar (PDA) containing $30 \mathrm{mg} \mathrm{L}^{-1}$ rifampin in 15 replicates per dilution and incubated at $26^{\circ} \mathrm{C}$ for 3-7 days. When fungal colonies appeared on the PDA plates, Trichoderma, Chaetomium, Penicillium, and Aspergillus spp. strains induced by the $\mathrm{BC} 0$ treatment were picked and inoculated onto new PDA plates to obtain pure strains. Morphological features such as colony, mycelium, and spore characteristics were used to avoid replication of the strains. The remaining strains were identified by amplification and sequencing of the respective ITS regions. The nucleotide sequences were analyzed using a similarity search against the GenBank database (Zheng et al., 2011).

The strains were cultivated using potato dextrose broth and then their mycelia were harvested by filtration through sterile gauze. Homogeneous suspensions of propagules were obtained by washing the mycelia with sterile distilled water and homogenizing the washed mycelia with a homogenizer. The experimental soil was mixed with a $P$. capsici zoospore suspension at a density of 100 zoospores per gram soil. The inoculated soil was divided into fungal treatment groups and one control. The fungal inoculation rate was $10 \mathrm{~g}$ fresh mycelia $/ \mathrm{kg}$ soil. The soil inoculated with the pathogen only was set as the control. Each treatment was replicated three times, and there were 15 pepper plants for each replicate. One 5-weekold pepper plant was grown in a pot containing $600 \mathrm{~g}$ of soil. All plants were acclimated in the greenhouse for 45 days, as mentioned above. The disease severity was determined at 15 and 30 days after planting. The disease index was assessed as described previously. The biocontrol efficacy was assessed using the following equation: Biocontrol efficacy $=[($ disease index under control - disease index under fungal treatment)/disease index under control] $\times 100 \%$. 


\section{Data Analysis}

All data were analyzed with the SPSS 19.0 software package (IBM, United States). Statistical significance between the treatments was tested with one-way analysis of variance (ANOVA). $p<0.05$ was considered statistically significant.

\section{RESULTS}

\section{Effect on Disease Severity and Pathogen Abundance}

As shown in Figure 1A, the disease indices of all treatments continued to increase with longer growing period. Biochar amendment significantly alleviated the disease development rate and disease indices compared to CK. In addition, the disease index of $\mathrm{BC} 0$ was reduced compared to that of $\mathrm{BC} 20$. The disease indices of $\mathrm{BC} 0$ and $\mathrm{BC} 20$ on day 15 were reduced by 91 and $72 \%$
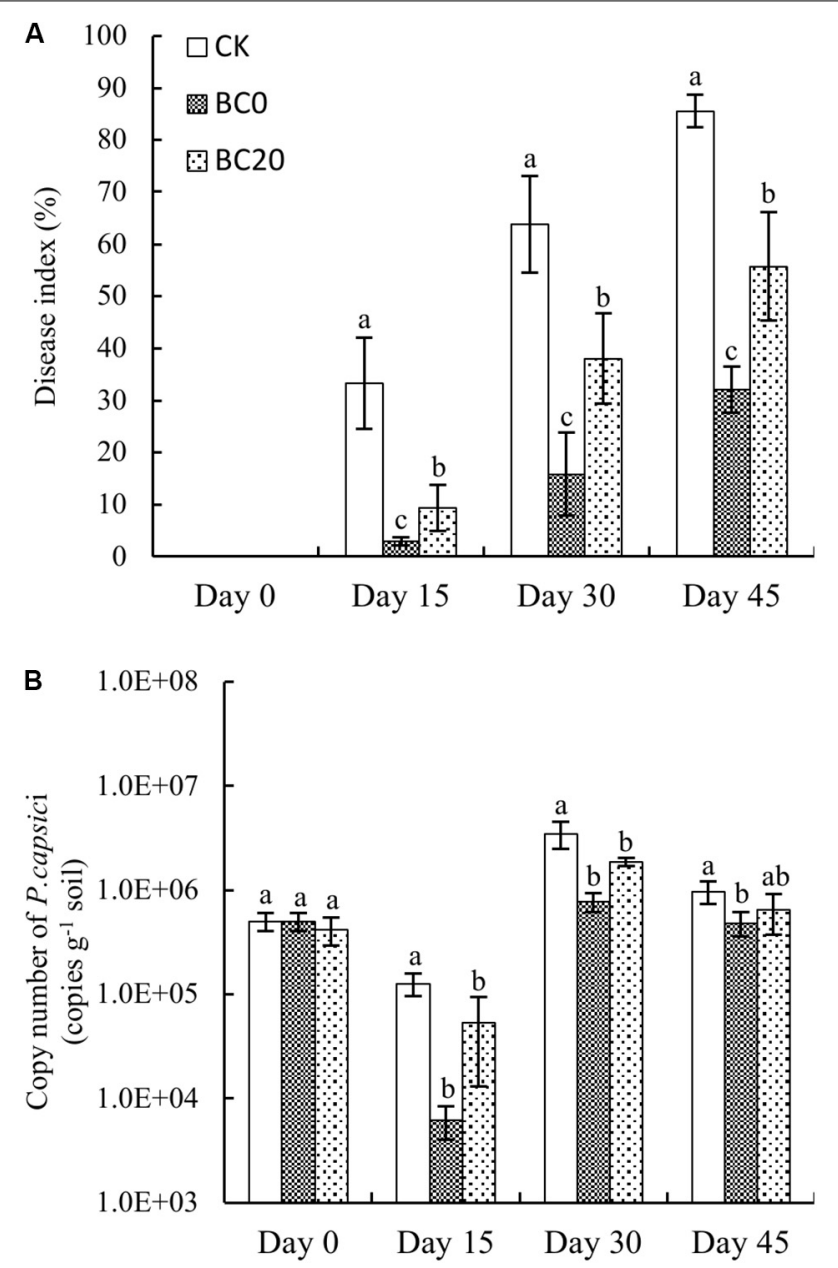

FIGURE 1 | Temporal effects of biochar applied at different times on the disease index (A) and abundance of Phytophthora capsici (B) during the growing period. Bars represent average values \pm standard error. Different letters above columns indicate significant differences $(p<0.05)$ according to one-way ANOVA $(n=3)$. compared to those of $\mathrm{CK}$, and those on day 45 were reduced by 63 and 35\%, respectively. This suggested that biochar amendment reduced disease development and that the control effect of $\mathrm{BC} 0$ was stronger than that of BC20.

The pathogen abundance in each treatment decreased by day 15 and then increased by day 30, followed by a gradual decrease on day 45 (Figure 1B). The pathogen abundance under the biochar treatments was significantly reduced relative to that under $\mathrm{CK}$, and that under $\mathrm{BC} 0$ was significantly reduced compared to that under BC20 during the entire growing period. In comparison, pathogen abundance under $\mathrm{BC} 0$ and BC20 on day 15 after planting was reduced by 95 and 58\%, respectively, and by 50 and $34 \%$, respectively, on day 45 after planting. Notably, biochar-induced suppression of $P$. capsici diminished over time.

\section{Effect on Soil Chemical Properties and Fungal Communities After Incubation for 20 Days}

\section{Chemical Properties}

The soil chemical properties changed to varying degrees after amendment with biochar and incubation for 20 days (Supplementary Table S1). Biochar amendment markedly increased the EC and contents of organic matter, available P, and available $\mathrm{K}$, which were correlated with the high contents of ash, organic matter, available $\mathrm{P}$, and available $\mathrm{K}$ in the biochar.

\section{Fungal Abundance and Community Composition}

The qPCR results suggested a significantly reduced abundance of total fungi and a significantly increased abundance of C. globosum, Aspergillus, Penicillium, and Trichoderma 20 days after the amendment of the soil with biochar (Figures 2A,B). In addition, the results of high-throughput sequencing indicated a reduced relative abundance of Cladosporium and Emericella. Furthermore, biochar significantly increased the relative abundance of Chaetomium, Funneliformis, Penicillium, and Trichoderma (Supplementary Figure S1). Therefore, although biochar amendment significantly reduced the total fungal abundance after 20 days of incubation, it increased the abundance of potential biocontrol fungi.

\section{Effect of on Soil Chemical Properties and Fungal Community During Planting Chemical Properties}

Both biochar treatments significantly increased the soil pH, EC, and contents of organic matter, available $\mathrm{P}$, and available $\mathrm{K}$ compared with CK during the entire growing period (Figure 3). The difference between biochar treatments, however, was not significant. The promotion of $\mathrm{pH}$, available $\mathrm{P}$, and available $\mathrm{K}$ by biochar amendment gradually declined with extended planting time. Compared to $\mathrm{CK}, \mathrm{BC} 0$ and $\mathrm{BC} 20$ had 1.36 and $1.11 \%$ higher $\mathrm{pH}$ values before planting, which decreased by 0.64 and $0.54 \%$ at 45 days after planting, respectively. Similarly, the available $\mathrm{P}$ content increased significantly by 19.13 and $21.38 \%$ before planting in $\mathrm{BC} 0$ and $\mathrm{BC} 20$, but at 45 days after planting, the differences were only 9.02 and $3.40 \%$, respectively. The available 

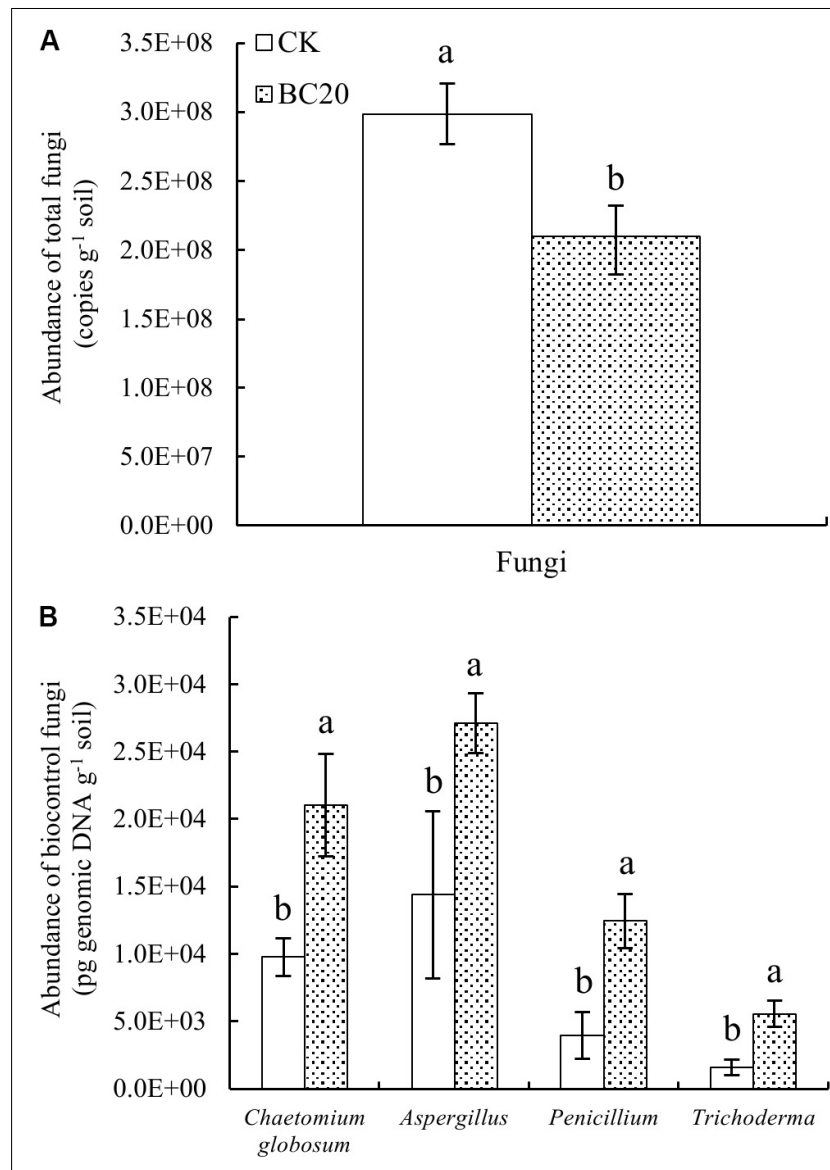

FIGURE 2 | Effect of biochar amendment on the abundance of total fungi (A) and potential rhizosphere-associated biocontrol fungi (B) after incubation for 20 days. Bars represent the standard error of each mean. Different letters above columns indicate significant differences $(p<0.05)$ according to one-way ANOVA $(n=3)$.

K contents were 259 and 271\% higher in BC0 and BC20 before planting and were still 161 and 155\% higher than CK at 45 days after planting, respectively. Thus, biochar-induced changes in soil nutrient qualities and chemical properties were only slightly affected by the time after biochar application, but more obviously affected by the planting time.

\section{Fungal Richness and Diversity}

The community richness indices, OTUs, Chaol, and ACE values were higher under the biochar treatments than under $\mathrm{CK}$, and significant differences in the OTUs and Chaol values were observed at 30 days after planting (Table 1). The Shannon diversity indices of the biochar treatments were higher than those of the CK, but significant difference was not observed. No significant difference in the richness and diversity indices was observed between $\mathrm{BC} 0$ and $\mathrm{BC} 20$.

\section{Fungal Community Composition}

A comparison of the relative abundance of the different fungal genera with an abundance of $>1 \%$ revealed significant differences with respect to the different treatments at 30 days after planting (Figure 4). The dominant genera were Mortierella (27.94-45.19\%), Cephaliophora (7.82-19.66\%), Chaetomium (3.84-14.35\%), Pseudaleuria (2.67-9.12\%), and Penicillium (5.62-6.30\%), followed by several other genera including Emericella, Aspergillus, Trichoderma, etc. PCoA clearly revealed that biochar amendment shifted the rhizosphere fungal community. In addition, the fungal community of BC0 was clearly separated from that of BC20 (Figure 5).

Groups 1 and 2 in Table 2 included the fungal genera that were higher and lower in relative abundance, respectively, in response to the biochar treatments. Significantly higher relative abundance of Chaetomium and Trichoderma and significantly lower abundance of Alternaria and Cladosporium were observed under the biochar treatments than under CK. Biochar treatments also enriched the genera Conocybe, Paecilomyces, and Arthrographis and depleted Cephaliophora and Aspergillus. In addition, BCO and BC20 had different effects on several fungal genera, as observed for group 3. BC0 significantly increased the relative abundance of Mortierella by $17.25 \%$ and reduced those of Pseudaleuria, Emericella, and Pyrenochaetopsis by 7.16, 10.45, and 2.09\%, respectively, compared with BC20.

\section{Fungal Abundance}

The qPCR results showed that the fungal abundance increased significantly under BC20 compared with that under $\mathrm{CK}$ after pepper planting (Figure 6A). BC0 resulted in a consistently higher fungal abundance during the entire growing period than $\mathrm{CK}$. Fungal abundance under $\mathrm{BC} 0$ was higher than that under BC20 at 30 and 45 days after planting, but the differences were not significant. In addition, the differences in fungal abundance between the CK and biochar treatments gradually decreased, suggesting a diminishing biochar-mediated proliferative effect on rhizosphere fungi over time.

Figures 6B-E indicate that the abundance of C. globosum, Aspergillus, and Penicillium under BC20 subsequently increased slightly and then deceased rapidly, but remained higher than that under CK. BC0 showed a strong enrichment of these biocontrol fungi during the entire growing period. The biocontrol fungal abundance under $\mathrm{BC} 0$ was higher or significantly higher than under BC20 at 30 and 45 days after planting. Compared to CK, the abundance of C. globosum, Aspergillus, Penicillium, and Trichoderma increased 0.46-, 4.56-, 2.48-, and 5.37-fold, respectively, under $\mathrm{BC} 0$ and by $1.14-, 0.12-, 0.37-$, and $0.44-$ fold, respectively, under BC20 at 45 days after planting. Thus, the shorter the duration of biochar in the soil, the stronger the increase in the abundance of biocontrol fungi it induced.

\section{Correlation Analyses of Fungal Abundance and Disease Severity}

Table 3 shows that the abundance of $P$. capsici correlated positively $(p<0.01)$ with the disease index. The abundance of $P$. capsici correlated negatively $(p<0.01)$ with the abundance of C. globosum, Aspergillus, and Penicillium as well as with Trichoderma at $p>0.05$. Similarly, disease severity correlated negatively $(p<0.01)$ with the abundance of C. globosum, Aspergillus, and Penicillium as well as with the abundance of Trichoderma at $p<0.05$. In addition, the total fungal abundance 


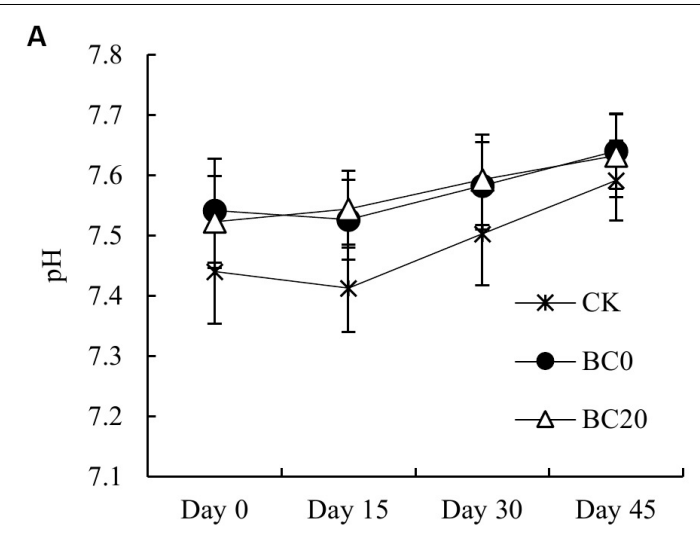

C
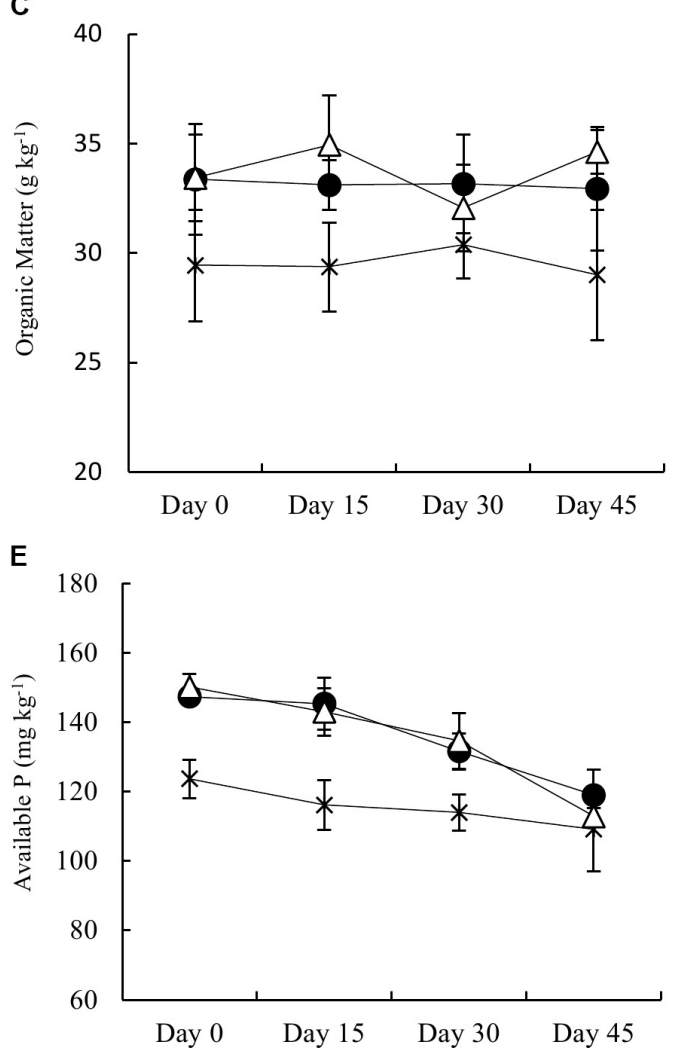

B

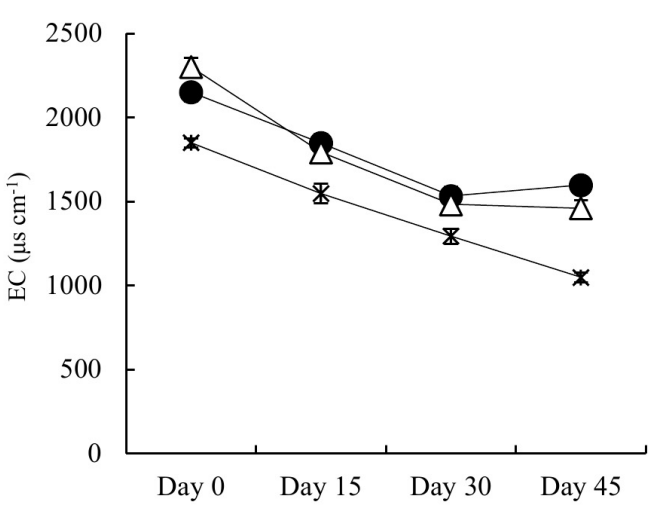

D

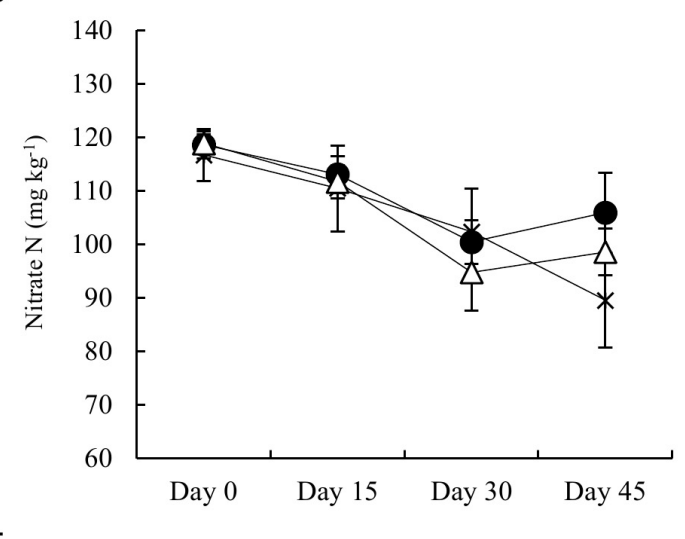

$\mathbf{F}$

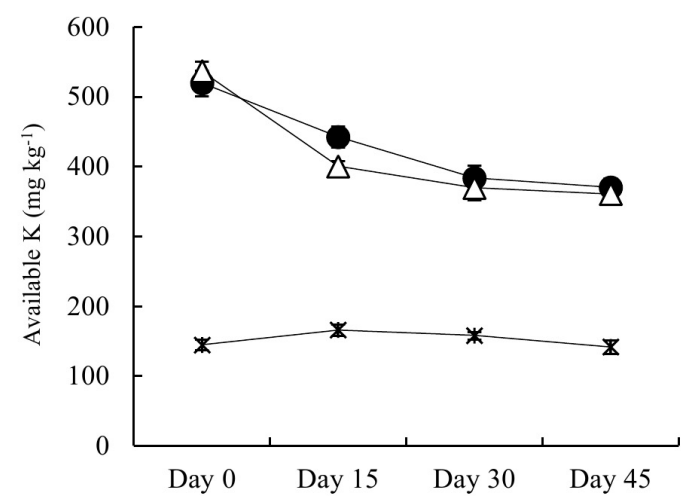

FIGURE 3 | Temporal effects of biochar applied at different times on soil chemical properties during the growing period. Soil chemical properties included pH (A), electrical conductivity (B), organic matter (C), nitrate nitrogen (D), available P (E), and available K (F). Bars represent average values \pm standard errors $(n=3)$.

correlated negatively with both the disease index and abundance of $P$. capsici at $p<0.05$. These correlations suggested that the abundance of total fungi, C. globosum, Aspergillus, Penicillium, and Trichoderma may be the important factor that suppresses the pathogen and controls Phytophthora blight of pepper in response to biochar amendment.

\section{Biocontrol Efficacy of Biochar-Enriched Biocontrol Fungi}

Two Aspergillus strains, three Chaetomium strains, three Penicillium strains, and three Trichoderma strains enriched by
BC0 were screened by comparing their colony characteristics on PDA plates from $\mathrm{CK}$ and $\mathrm{BC}$. The results of the molecular identification are shown in Supplementary Table S2. Two Aspergillus (AS1 and AS2), two Chaetomium (CH1 and $\mathrm{CH} 3$ ), three Penicillium (PE1, PE2, and PE3), and two Trichoderma (TR1 and TR3) strains were confirmed to be enriched in response to biochar amendment according to their colonizations in the rhizospheres with and without biochar amendment (data not shown).

In the pot experiment, nine antagonistic fungi showed major variations in the reduction of disease severity (Table 4). At 15 days after planting, Penicillium PE1 had no control effect. 
TABLE 1 | Fungal richness and diversity indices at 30 days after transplanting.

\begin{tabular}{lccccc}
\hline & OTUs & ACE & Chao1 & Coverage & Shannon \\
\hline CK & $235 \pm 19 \mathrm{~b}$ & $456 \pm 98 \mathrm{~b}$ & $372 \pm 70 \mathrm{~b}$ & $0.962 \pm 0.009 \mathrm{a}$ & $3.36 \pm 0.27 \mathrm{a}$ \\
$\mathrm{BCO}$ & $297 \pm 12 \mathrm{a}$ & $595 \pm 59 \mathrm{a}$ & $492 \pm 27 \mathrm{a}$ & $0.951 \pm 0.006 \mathrm{a}$ & $3.60 \pm 0.15 \mathrm{a}$ \\
$\mathrm{BC} 20$ & $284 \pm 24 \mathrm{a}$ & $649 \pm 137 \mathrm{a}$ & $466 \pm 59 \mathrm{ab}$ & $0.950 \pm 0.013 \mathrm{a}$ & $3.75 \pm 0.26 \mathrm{a}$
\end{tabular}

OTUs, operational taxonomic units; ACE, abundance-based coverage estimation; Chao1, Chao estimator of microbial richness; Coverage, Good's coverage index; Shannon, Shannon diversity index. Different letters after the values in the same column indicate significant differences $(p<0.05)$ according to oneway ANOVA $(n=3)$.

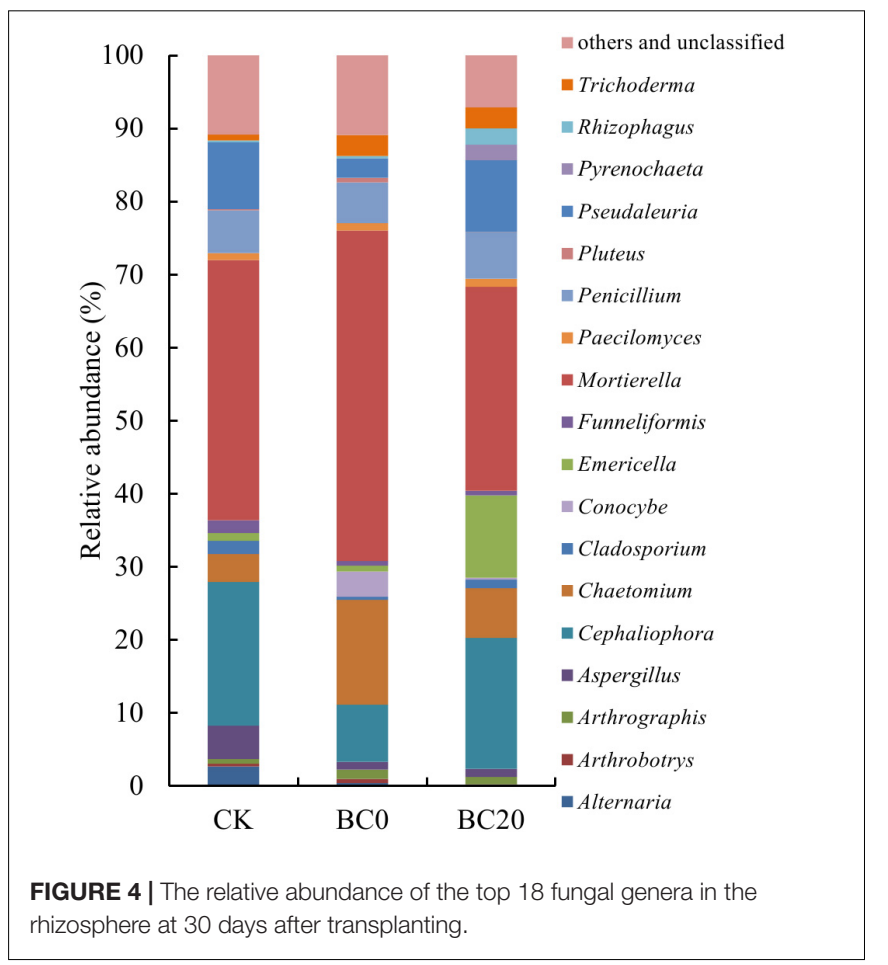

The control efficacies of the other eight fungal strains were in the range of 18.27-59.62\%. In particular, Aspergillus AS1 had the highest control efficacy of $59.62 \%$, followed by $51.92 \%$ and 45.19\% for Trichoderma TR3 and TR1, respectively, and 44.23\% for Chaetomium CH1. The disease indices of all treatments increased with extended planting time, while the control efficacies of the biocontrol strains continued to decline. At 30 days after planting, the control efficacy of Trichoderma TR3 was $30.53 \%$, representing the best biocontrol strain, followed by 24.43\% for Aspergillus AS1. In addition, the control efficacies of two Chaetomium strains were 17.37 and $19.08 \%$, while of the Penicillium strains, only PE3 had a control efficacy of $15.27 \%$. In short, the Aspergillus and Trichoderma strains had the best control effect, followed by the Chaetomium strains, and then the Penicillium strains.

The abundance of $P$. capsici and the disease indices of all treatments showed the same trend, i.e., a high disease index indicated high pathogen abundance. All seven biocontrol strains (except PE1 and PE3), which showed a control effect, were associated with a significantly lower abundance of $P$. capsici

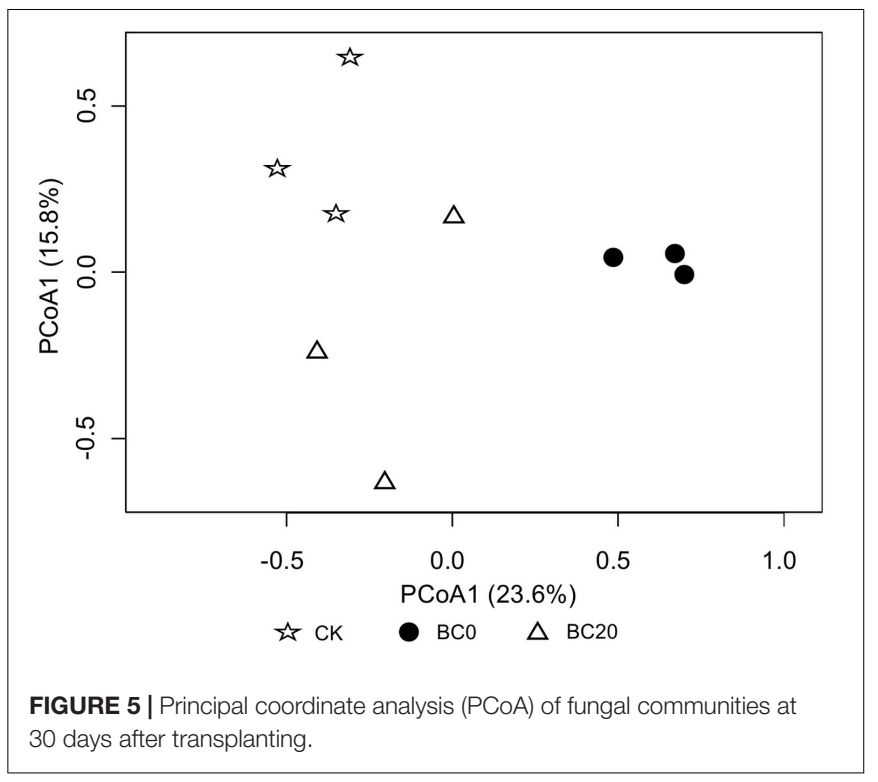

TABLE 2 | Fungal genera (average relative abundance > 1\%) significantly changed by biochar amendment at 30 days after transplanting.

\begin{tabular}{|c|c|c|c|c|}
\hline & & CK & $\mathrm{BCO}$ & BC20 \\
\hline \multirow[t]{5}{*}{ Group 1} & Chaetomium & $3.84 \pm 1.26 b$ & $14.35 \pm 3.31 a$ & $6.82 \pm 4.42 b$ \\
\hline & Trichoderma & $0.78 \pm 0.53 b$ & $2.86 \pm 0.41 a$ & $2.88 \pm 0.93 a$ \\
\hline & Conocybe & $\mathrm{Oa}$ & $3.42 \pm 2.93 a$ & $0.26 \pm 0.15 a$ \\
\hline & Paecilomyces & $0.94 \pm 0.28 a$ & $1.02 \pm 0.14 \mathrm{a}$ & $1.10 \pm 0.34 a$ \\
\hline & Arthrographis & $0.65 \pm 0.25 a$ & $1.28 \pm 0.43 a$ & $0.99 \pm 0.47 a$ \\
\hline \multirow[t]{4}{*}{ Group 2} & Cephaliophora & $19.66 \pm 13.08 a$ & $7.82 \pm 0.79 a$ & $17.91 \pm 4.99 a$ \\
\hline & Aspergillus & $4.54 \pm 3.34 a$ & $1.02 \pm 0.63 a$ & $1.12 \pm 0.30 a$ \\
\hline & Cladosporium & $1.83 \pm 0.32 a$ & $0.44 \pm 0.16 b$ & $1.15 \pm 1.02 \mathrm{ab}$ \\
\hline & Alternaria & $2.69 \pm 1.34 a$ & $0.42 \pm 0.32 b$ & $0.10 \pm 0.08 b$ \\
\hline \multirow[t]{4}{*}{ Group 3} & Mortierella & $35.59 \pm 6.59 \mathrm{ab}$ & $45.19 \pm 4.36 \mathrm{a}$ & $27.94 \pm 4.36 b$ \\
\hline & Pseudaleuria & $9.12 \pm 3.30 a$ & $2.67 \pm 1.23 b$ & $9.83 \pm 1.88 a$ \\
\hline & Emericella & $1.07 \pm 0.18 b$ & $0.84 \pm 0.35 b$ & $11.29 \pm 5.46 a$ \\
\hline & Pyrenochaetopsis & $\mathrm{Ob}$ & $\mathrm{Ob}$ & $2.09 \pm 1.62 a$ \\
\hline
\end{tabular}

Different letters after the values in the same row indicate significant differences $(p<0.05)$ according to one-way ANOVA $(n=3)$. Group 1 includes the fungal genera with higher relative abundances under the biochar treatments. Group 2 includes fungal genera with lower relative abundances under the biochar treatments. Group 3 includes fungal genera that responded differently to the biochar treatments.

than the control. The pathogen abundance among the seven treatments with similar control effects did not differ significantly.

\section{DISCUSSION}

Biochar demonstrated its possibility as a control agent against Phytophthora blight of pepper, supporting similar control effects of soilborne diseases observed in previous studies (Jaiswal et al., 2017; Zhang et al., 2017; Gao et al., 2019; Jaiswal et al., 2019; Chen et al., 2020). Furthermore, biochar applied before planting showed a significantly higher control effect than that applied 20 days before planting, indicating its declining control effect with prolonged application time prior 


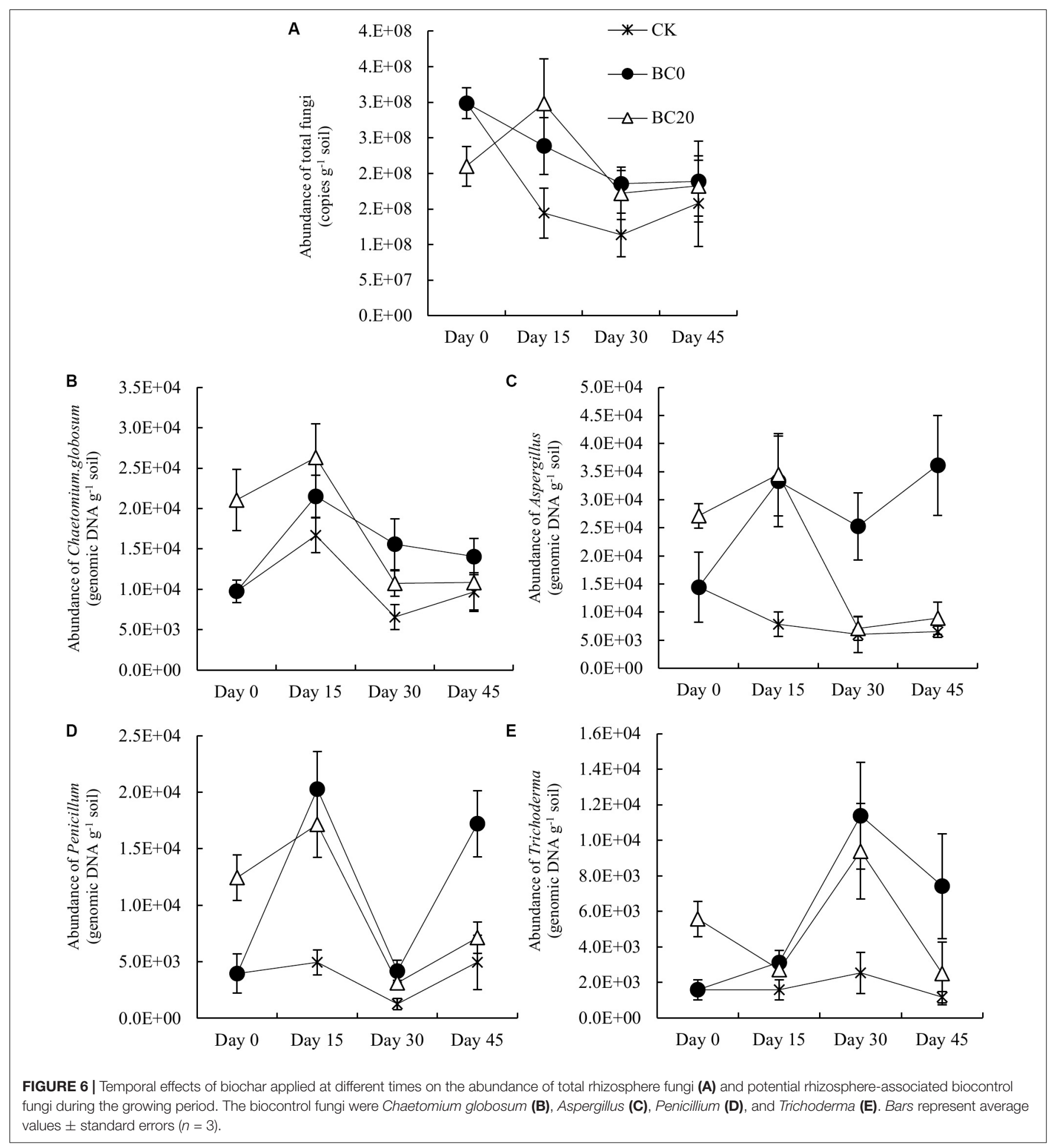

to pepper planting. We assessed the chemical properties, fungal community composition, and abundance of potential biocontrol fungi in the rhizosphere soil, providing novel insights into the mechanisms underlying the biochar-mediated control of soilborne diseases.

Supporting previous studies (Gul et al., 2015; Yao et al., 2017; Zhang et al., 2017; Chen et al., 2020), biochar amendment directly affected the soil chemical properties, in particular soil $\mathrm{pH}, \mathrm{EC}$, and the contents of organic matter, available $\mathrm{P}$, and available $\mathrm{K}$. Elemental $\mathrm{P}$ and $\mathrm{K}$ can promote sugar and protein metabolism in plants, stimulate root growth, accelerate root absorption, and effectively alleviate root diseases (Gupta et al., 2017). Zhang et al. (2017) and Chen et al. (2020) reported that biochar-induced changes in the soil chemical 
TABLE 3 | Relationship of disease severity and pathogen abundance to fungal abundance based on correlation analysis of multi-time point data (15, 30, and 45 days after transplanting).

\begin{tabular}{lcc}
\hline & Disease severity & Phytophthora capsici \\
\hline P. capsici & $0.532^{\star \star}$ & - \\
Total fungi & $-0.441^{\star}$ & $-0.425^{\star}$ \\
C. globosum & $-0.759^{\star \star}$ & $-0.667^{\star \star}$ \\
Aspergillus & $-0.707^{\star \star}$ & $-0.518^{\star \star}$ \\
Penicillium & $-0.597^{\star \star}$ & $-0.621^{\star \star}$ \\
Trichoderma & $-0.446^{\star}$ & -0.307 \\
\hline
\end{tabular}

*Significant at $p<0.05 ;{ }^{* *}$ Highly significant at $p<0.01$.

properties were favorable for beneficial microorganisms, but unfavorable for Ralstonia and bacterial wilt. Similarly, in our study, the increases in $\mathrm{pH}, \mathrm{EC}$, and contents of available $\mathrm{P}$ and available $\mathrm{K}$ caused by biochar amendment were conducive to increasing the relative abundance of beneficial fungi, such as Trichoderma, Chaetomium, Penicillium, Emericella, and Paecilomyces (Supplementary Figure S2). In addition, the soil EC and the contents of organic matter, available P, and available $\mathrm{K}$ correlated significantly and negatively with the abundance of pathogens and disease severity (Supplementary Table S3), indicating a significant association between the soil chemical properties and disease suppression in response to biochar amendment. As there was little difference between $\mathrm{BC} 0$ and $\mathrm{BC} 20$ in terms of soil chemical properties, the difference in the disease control effect between these two biochar treatments was most likely due to the differences in the microbial properties within the rhizosphere.

Fungal abundance significantly increased in the biocharamended soils, which was in agreement with the results of Bamminger et al. (2014) and Yao et al. (2017). Although this stimulation was weakened with extended planting time, fungal abundance in the biochar-amended soils was still greater than that in unamended soils during the growing period. Zhang et al. (2017), Jaiswal et al. (2018), and Li et al. (2019) indicated that biochar amendment positively influences fungal richness and diversity. Supporting that, significantly higher fungal richness and diversity indices were found in the biochar-amended soils. Many studies have documented that soil microbial richness and diversity and the ratio of pathogens to fungi may contribute to soil disease suppression (Bender et al., 2016; Frạc et al., 2018; Huang et al., 2018; Saleem et al., 2019), suggesting that the lower disease severity in the biochar treatments could be partly linked to the increased fungal abundance as well as fungal richness and diversity. However, the difference between BC0 and BC20 was small, indicating that the significant difference in disease control between the two biochar treatments was mostly due to the differences in the fungal community composition.

High-throughput sequencing revealed that the relative abundance of certain fungal genera significantly decreased or increased in response to biochar amendment. The relative abundance of Chaetomium, Paecilomyces, Penicillium, and Trichoderma was higher in the biochar-amended soils. These four genera have been reported to be linked to the promotion of plant growth, production of antibiotic compounds, induction of plant defenses, and suppression of soilborne disease (Howell, 2003; André and Schmoll, 2010; Sibounnavong et al., 2011; Khan et al., 2012; Prakob et al., 2012; Bladt et al., 2013; Shanthiyaa et al., 2013; Saldajeno et al., 2014). Another important finding was that the relative abundance of Alternaria and Cephaliophora, which may cause plant disease (Sweta et al., 2014; Mukesh et al., 2017), decreased under the biochar treatments, suggesting that biochar could suppress crop pathogens. The differences noted between the BC0 and BC20 treatments, such as a higher abundance of Chaetomium and a lower abundance of Cephaliophora, suggest that the BCO-induced fungal community may have a higher soilborne disease suppression ability.

Consistent with the high-throughput sequencing results, the qPCR results showed that the abundance of C. globosum, Penicillium, and Trichoderma significantly increased in the biochar-amended soils. However, the higher abundance of Aspergillus in the biochar treatments was in contrast to the

TABLE 4 | Disease severity, pathogen abundance, and control efficacy of beneficial fungi in Phytophthora capsici-infested pepper seedlings.

\begin{tabular}{|c|c|c|c|c|c|c|}
\hline Treatment & \multicolumn{3}{|c|}{15 days after transplanting } & \multicolumn{3}{|c|}{30 days after transplanting } \\
\hline PC & $36.11 \pm 6.67 a b$ & $16.53 \pm 1.53 a$ & - & $90.97 \pm 4.34 a b$ & $20.81 \pm 3.73 a$ & - \\
\hline$P C+A S 1$ & $14.58 \pm 6.98 d$ & $6.13 \pm 0.41 d$ & 59.62 & $68.75 \pm 10.42 c$ & $12.91 \pm 1.33 b c d$ & 24.43 \\
\hline $\mathrm{PC}+\mathrm{AS} 2$ & $20.83 \pm 6.38 c d$ & $5.27 \pm 0.36 d$ & 42.31 & $71.53 \pm 8.67 c$ & $8.12 \pm 1.07 e$ & 21.37 \\
\hline$P C+P E 1$ & $41.67 \pm 7.60 a$ & $11.26 \pm 0.97 b$ & -15.39 & $92.36 \pm 6.01 a$ & $20.69 \pm 2.94 a$ & -1.53 \\
\hline$P C+P E 2$ & $26.04 \pm 5.97 b c d$ & $12.09 \pm 2.65 b$ & 27.88 & $88.89 \pm 1.20 a b$ & $20.02 \pm 1.82 a$ & 2.29 \\
\hline$P C+P E 3$ & $29.51 \pm 7.39 b c$ & $9.93 \pm 0.84 b c$ & 18.27 & $77.08 \pm 2.08 b c$ & $15.15 \pm 1.42 b$ & 15.27 \\
\hline$P C+T R 1$ & $19.79 \pm 4.84 c d$ & $4.47 \pm 0.66 d$ & 45.19 & $72.22 \pm 10.69 c$ & $9.13 \pm 1.36 d e$ & 20.61 \\
\hline$P C+T R 3$ & $17.36 \pm 3.29 d$ & $3.82 \pm 0.75 d$ & 51.92 & $63.19 \pm 11.47 c$ & $10.19 \pm 2.54 c d e$ & 30.53 \\
\hline
\end{tabular}

Different letters after the values in the same column indicate significant differences $(p<0.05)$ according to one-way ANOVA $(n=3)$. Aspergillus strains: AS1 and AS2. Chaetomium strains: $\mathrm{CH} 1$ and $\mathrm{CH}$. Penicillium strains: PE1, PE2, and PE3. Trichoderma strains: TR1 and TR3. PC, soil not inoculated with biocontrol bacteria. 
results of the high-throughput sequencing. This may be related to the accuracy and adaptability of the two methods (Murray et al., 2011). The increased abundance of Aspergillus, Penicillium, and Trichoderma was probably related to the degradation of polycyclic aromatic hydrocarbons in the biochar via the production of enzymes (Anyika et al., 2015; Al-Hawash et al., 2018), which was in agreement with other studies (Jaiswal et al., 2017, 2018; Vecstaudza et al., 2018). Several authors have reported that C. globosum, Aspergillus, Penicillium, and Trichoderma could control plant diseases caused by Phytophthora spp. and suppress these pathogens (Fang and Tsao, 1995; Kang et al., 2005; Shanthiyaa et al., 2013; Widmer, 2014). Correlation analyses indicated that the biochar-mediated disease suppression was closely associated with the proliferation of C. globosum, Aspergillus, Penicillium, and Trichoderma. The biochar-mediated proliferation of biocontrol fungi may contribute to reducing the abundance of $P$. capsici due to the production of antibiotic compounds with activities against pathogens (Park et al., 2005; André and Schmoll, 2010; Bladt et al., 2013). The Aspergillus, Chaetomium, and Trichoderma strains enriched by the biochar exhibited strong suppression of $P$. capsici and Phytophthora blight of pepper. However, the Penicillium strains, except one, showed little control efficacy and failed to reduce the disease. Thus, the enrichment of Aspergillus, Chaetomium, and Trichoderma probably contributed much to the disease suppression effects of biochar.

We assumed that soil incubated with biochar for 20 days could form a soil microbial community that is adverse to soilborne pathogens, thereby improving the soil disease suppression. However, although the abundance of potential biocontrol fungi was high under BC20 before planting, the effect of this treatment on Phytophthora blight of pepper was profoundly reduced compared to that of $\mathrm{BC} 0$. The proliferation of pathogens and plant morbidity are time-dependent processes. In the mid- and late growing periods, the abundance of biocontrol fungi under $\mathrm{BC} 0$ was markedly increased relative to that under BC20, which is probably an important reason for the higher control effect of $\mathrm{BC} 0$.

Overall, our results indicate that biochar-induced improvement in the rhizosphere fungal community, especially the increased abundance of total fungi and beneficial fungi as well as the augmented fungal richness and diversity, conferred inhibition of $P$. capsici and Phytophthora blight of pepper. Biochar-mediated improvement of soil chemical properties had positive effects on beneficial soil fungi and disease suppression. The disease control effect of biochar was significantly weakened with a prolonged period between the

\section{REFERENCES}

Aggarwal, R., Sharma, S., Gupta, S., and Shukla, R. (2014). Development of conventional and real time PCR assay for the rapid detection and quantification of a biocontrol agent, Chaetomium globosum. J. Plant. Pathol. 96, 477-485. doi: 10.4454/JPP.V96I3.023

Al-Hawash, A. B., Alkooranee, J. T., Zhang, X., and Ma, F. (2018). Fungal degradation of polycyclic aromatic hydrocarbons. Int. J. Pure. App. Biosci. 6, 8-24. doi: 10.18782/2320-7051.6302 application and planting, which may be largely explained by the short-term promoting effect of biochar amendment on the abundance of biocontrol fungi, such as Aspergillus, Chaetomium, and Trichoderma. Further work is required to pinpoint more biochar-enriched microorganisms that contribute to disease suppression and to elucidate the contribution of each of these microorganisms on controlling soilborne disease.

\section{DATA AVAILABILITY STATEMENT}

The original DNA sequence data were deposited in the National Center for Biotechnology Information (NCBI) with accession number SRP224915.

\section{AUTHOR CONTRIBUTIONS}

GW, YM, and RG designed the study. GW performed the experiments and was involved with writing the manuscript. YM, RG, and HC contributed to revising the manuscript. JL participated in the greenhouse and lab work. RG helped with sequence data analysis. All authors contributed to the article and approved the submitted version.

\section{FUNDING}

This study was funded by the National Key Research and Development Program of China (2018YFD0201200), the "333 Project" Foundation of Jiangsu Province (BRA2019313), and the National Natural Science Foundation of China (31471949).

\section{ACKNOWLEDGMENTS}

We thank Professor Zubin Xie, Institute of Soil Science, Chinese Academy of Sciences, for providing the straw biochar.

\section{SUPPLEMENTARY MATERIAL}

The Supplementary Material for this article can be found online at: https://www.frontiersin.org/articles/10.3389/fmicb. 2020.01427/full\#supplementary-material

André, S., and Schmoll, M. (2010). Biology and biotechnology of Trichoderma. Appl. Microbiol. Biotechnol. 87, 787-799. doi: 10.1007/s00253-01 0-2632-1

Anyika, C., Majid, Z. A., Ibrahim, Z., Zakaria, M. P., and Yahya, A. (2015). The impact of biochars on sorption and biodegradation of polycyclic aromatic hydrocarbons in soils-a review. Environ. Sci. Pollut. R. 22, 3314-3341. doi: 10.1007/s11356-014-3719-5

Bamminger, C., Zaiser, N., Zinsser, P., Lamers, M., Kammann, C., and Marhan, S. (2014). Effects of biochar, earthworms, and litter addition on soil microbial 
activity and abundance in a temperate agricultural soil. Biol. Fert. Soils 50, 1189-1200. doi: 10.1007/s00374-014-0968-x

Bender, S. F., Wagg, C., and Der Heijden, M. G. (2016). An underground revolution: biodiversity and soil ecological engineering for agricultural sustainability. Trends. Ecol. Evol. 31, 440-452. doi: 10.1016/j.tree.2016. 02.016

Bladt, T., Frisvad, J., Knudsen, P., and Larsen, T. (2013). Anticancer and antifungal compounds from Aspergillus, Penicillium and other filamentous fungi. Molecules 18, 11338-11376. doi: 10.3390/molecules 180911338

Bokulich, N. A., and Mills, D. A. (2013). Improved selection of internal transcribed spacer-specific primers enables quantitative, ultra-high-throughput profiling of fungal communities. Appl. Environ. Microb. 79, 2519-2526. doi: 10.1128/AEM. 03870- 12

Chen, S., Qi, G., Ma, G., and Zhao, X. (2020). Biochar amendment controlled bacterial wilt through changing soil chemical properties and microbial community. Microbiol. Res. 231;126373. doi: 10.1016/j.micres.2019.126373

Egamberdieva, D., Wirth, S., Behrendt, U., Abd_Allah, E. F., and Berg, G. (2016). Biochar treatment resulted in a combined effect on soybean growth promotion and a shift in plant growth promoting rhizobacteria. Front. Microbiol. 7:209. doi: 10.3389/fmicb.2016.00209

Elmer, W. H. (2016). Effect of leaf mold mulch, biochar, and earthworms on mycorrhizal colonization and yield of asparagus affected by Fusarium crown and root rot. Plant. Dis. 100, 2507-2512. doi: 10.1094/PDIS-10-15-1196-RE

Fang, J. G., and Tsao, P. H. (1995). Efficacy of Penicillium funiculosum as a biological control agent against Phytophthora root rots of Azalea and citrus. Phytopathology 85, 871-878. doi: 10.1094/Phyto-85-871

Farrell, M., Kuhn, T. K., Macdonald, L. M., Maddern, T., Murphy, D. V., Hall, P. A., et al. (2013). Microbial utilisation of biochar-derived carbon. Sci. Total. Environ. 465, 288-297. doi: 10.1016/j.scitotenv.2013.03.090

Frạc, M., Hannula, S. E., Bełka, M., and Jędryczka, M. (2018). Fungal biodiversity and their role in soil health. Front. Microbiol. 9:707. doi: 10.3389/fmicb.2018. 00707

Gao, Y., Lu, Y., Lin, W., Tian, J., and Cai, K. (2019). Biochar suppresses bacterial wilt of tomato by improving soil chemical properties and shifting soil microbial community. Microorganisms. 7:676. doi: 10.3390/microorganisms7120676

Goebes, M. D., Hildemann, L. M., Kujundzic, E., and Hernandez, M. (2007). Realtime PCR for detection of the Aspergillus genus. J. Environ. Monitor. 9, 599-609. doi: $10.1039 / \mathrm{b} 618937 \mathrm{~g}$

Gul, S., Whalen, J. K., Thomas, B. W., Sachdeva, V., and Deng, H. (2015). Physico-chemical properties and microbial responses in biochar-amended soils. Mechanisms and future directions. Agr. Ecosyst. Environ. 206, 46-59. doi: 10. 1016/j.agee.2015.03.015

Gupta, N., Debnath, S., Sharma, S., Sharma, P., and Purohit, J. (2017). "Role of nutrients in controlling the plant diseases in sustainable agriculture," in Agriculturally Important Microbes for Sustainable Agriculture, eds V. S. Meena, P. K. Mishra, J. K. Bisht, and A. Pattanayak (Berlin: Springer). doi: 10.1007/978981-10-5343-6_8

Hagn, A., Wallisch, S., Radl, V., Munch, J. C., and Schloter, M. (2007). A new cultivation independent approach to detect and monitor common Trichoderma species in soils. J. Microbiol. Meth. 69, 86-92. doi: 10.1016/j.mimet.2006.12.004

Howell, C. R. (2003). Mechanisms employed by Trichoderma species in the biological control of plant diseases: the history and evolution of current concepts. Plant. Dis. 87, 4-10. doi: 10.1094/PDIS.2003.87.1.4

$\mathrm{Hu}, \mathrm{L}$, Cao, L., and Zhang, R. (2014). Bacterial and fungal taxon changes in soil microbial community composition induced by short-term biochar amendment in red oxidized loam soil. World J. Microb. Biot. 30, 1085-1092. doi: 10.1007/ s11274-013-1528-5

Huang, Y., Xiao, X., Huang, H., Jing, J., Zhao, H., Wang, L., et al. (2018). Contrasting beneficial and pathogenic microbial communities across consecutive cropping fields of greenhouse strawberry. Appl. Microbiol. Biotechnol. 102, 5717-5729. doi: 10.1007/s00253-018-9013-6

Jaiswal, A. K., Elad, Y., Cytryn, E., Graber, E. R., and Frenkel, O. (2018). Activating biochar by manipulating the bacterial and fungal microbiome through preconditioning. New. Phytol. 219, 363-377. doi: 10.1111/nph.15042

Jaiswal, A. K., Elad, Y., Graber, E. R., and Frenkel, O. (2014). Rhizoctonia solani suppression and plant growth promotion in cucumber as affected by biochar pyrolysis temperature, feedstock and concentration. Soil. Biol. Biochem. 69, 110-118. doi: 10.1016/j.soilbio.2013.10.051
Jaiswal, A. K., Elad, Y., Paudel, I., Graber, E. R., Cytryn, E., and Frenkel, O. (2017). Linking the belowground microbial composition, diversity and activity to soilborne disease suppression and growth promotion of tomato amended with biochar. Sci. Rep. 7:44382. doi: 10.1038/srep44382

Jaiswal, A. K., Frenkel, O., Elad, Y., Lew, B., and Graber, E. R. (2015). Nonmonotonic influence of biochar dose on bean seedling growth and susceptibility to Rhizoctonia solani: the "Shifted Rmax-Effect". Plant. Soil 395, 125-140. doi: 10.1007/s11104-014-2331-2

Jaiswal, A. K., Graber, E. R., Elad, Y., and Frenkel, O. (2019). Biochar as a management tool for soilborne diseases affecting early stage nursery seedling production. Crop. Prot. 120, 34-42. doi: 10.1016/j.cropro.2019.02.014

Jiang, X., Denef, K., Stewart, C. E., and Cotrufo, M. F. (2016). Controls and dynamics of biochar decomposition and soil microbial abundance, composition, and carbon use efficiency during long-term biocharamended soil incubations. Biol. Fert. Soils 52, 1-14. doi: 10.1007/s00374-01 5-1047-7

Kang, S. W., Hong, S. I., and Kim, S. W. (2005). Identification of Aspergillus strain with antifungal activity against Phytophthora species. J. Microb. Biot. 15, 227-233. doi: 10.1007/s10295-005-0222-5

Khan, A. L., Hamayun, M., Kang, S. M., Kim, Y. H., Jung, H. Y., Lee, J. H., et al. (2012). Endophytic fungal association via gibberellins and indole acetic acid can improve plant growth under abiotic stress, an example of Paecilomyces formosus LHL10. BMC Microbiol. 12:3. doi: 10.1186/1471-21 $80-12-3$

Kõljalg, U., Nilsson, R. H., Abarenkov, K., Tedersoo, L., Taylor, A. F. S., Bahram, M., et al. (2013). Towards a unified paradigm for sequence-based identification of fungi. Mol. Ecol. 22, 5271-5277. doi: 10.1111/mec.12481

Lehmann, J., Rillig, M. C., Thies, J., Masiello, C. A., Hockaday, W. C., and Crowley, D. (2011). Biochar effects on soil biota - A review. Soil Biol. Biochem. 43, 1812-1836. doi: 10.1016/j.soilbio.2011.04.022

Li, Y., Yang, Y., Shen, F., Tian, D., Zeng, Y., Yang, G., et al. (2019). Partitioning biochar properties to elucidate their contributions to bacterial and fungal community composition of purple soil. Sci. Total. Environ. 648, 1333-1341. doi: 10.1016/j.scitotenv.2018.08.222

Lu, Y., Rao, S., Huang, F., Cai, Y., Wang, G., and Cai, K. (2016). Effects of biochar amendment on tomato bacterial wilt resistance and soil microbial amount and activity. Int. J. Agron. 3, 1-10. doi: 10.1155/2016/2938282

Meng, L., Sun, T., Li, M., Saleem, M., Zhang, Q., and Wang, C. (2019). Soilapplied biochar increases microbial diversity and wheat plant performance under herbicide fomesafen stress. Ecotox. Environ. Safe 171, 75-83. doi: 10. 1016/j.ecoenv.2018.12.065

Mukesh, M., Gupta, S. K., Prashant, S., Andleeb, Z., Dubey, M. K., and Upadhyay, R. S. (2017). Alternaria toxins: potential virulence factors and genes related to pathogenesis. Front. Microbiol. 8:1451. doi: 10.3389/fmicb.2017. 01451

Murray, D. C., Bunce, M., Cannell, B. L., Oliver, R., Houston, J., White, N. E., et al. (2011). DNA-based faecal dietary analysis: a comparison of qPCR and high throughput sequencing approaches. PLoS One 6:e25776. doi: 10.1371/journal. pone. 0025776

Nair, V. D., Nair, P. K., Dari, B., Freitas, A. M., Chatterjee, N., and Pinheiro, F. M. (2017). Biochar in the agroecosystem-climate-change-sustainability nexus. Front. Plant. Sci. 8:2051. doi: 10.3389/fpls.2017.02051

Park, J. H., Choi, G. J., Jang, K. S., Lim, H. K., Kim, H. T., Cho, K. Y., et al. (2005). Antifungal activity against plant pathogenic fungi of chaetoviridins isolated from Chaetomium globosum. FEMS. Microbiol. Lett. 252, 309-313. doi: 10.1016/j.femsle.2005.09.013

Prakob, W., Nguen-Hom, J., Jaimasit, P., and Silapapongpri, S. (2012). Biological control of lettuce root-knot disease by the used of Pseudomonas aeruginosa, Bacillus subtilis and Paecilomyces lilacinus. J. Agr. Tech. 5, 179-191.

Saldajeno, M. G. B., Naznin, H. A., Elsharkawy, M. M., Shimizu, M., and Hyakumachi, M. (2014). "Enhanced resistance of plants to disease using Trichoderma spp," in Biotechnology and Biology of Trichoderma, eds V. G. Gupta, M. Schmoll, A. Herrera-Estrella, R. S. Upadhyay, I. Druzhinina, and M. Tuohy (London: Newnes Press), 477-493. doi: 10.1016/B978-0-444-59576-8. 00035-7

Saleem, M., Hu, J., and Jousset, A. (2019). More than the sum of its parts: microbiome biodiversity as a driver of plant growth and soil health. Annu. 
Rev. Ecol. Evol. Sci. 50, 145-168. doi: 10.1146/annurev-ecolsys-110617-16 2605

Schloss, P. D., Westcott, S. L., Ryabin, T., Hall, J. R., Hartmann, M., Hollister, E. B., et al. (2009). Introducing Mothur, open-source, platform-independent, community-supported software for describing and comparing microbial communities. Appl. Environ. Microb. 75, 7537-7541. doi: 10.1128/AEM.0154109

Shanthiyaa, V., Saravanakumar, D., Rajendran, L., Karthikeyan, G., Prabakar, K., and Raguchander, T. (2013). Use of Chaetomium globosum for biocontrol of potato late blight disease. Crop. Prot. 52, 33-38. doi: 10.1016/j.cropro.2013.05. 006

Sibounnavong, P., Soytong, K., Makhonpas, C., and Adthajadee, A. (2011). Evaluation of Chaetomium-mycephyt to promote the growth of Kale. J. Agr. Tech. 7, 2231-2237.

Sohi, S., Krull, E. S., Lopezcapel, E., and Bol, R. (2010). A review of biochar and its use and function in soil. Adv. Agron. 105, 47-82. doi: 10.1016/S0065-2113(10) 05002-9

Suanthie, Y., Cousin, M. A., and Woloshuk, C. P. (2009). Multiplex real-time PCR for detection and quantification of mycotoxigenic Aspergillus, Penicillium and Fusarium. J. Stored. Prod. Res. 45, 139-145. doi: 10.1016/j.jspr.2008.12.001

Sweta, S., Ravindra, K., Gupta, G. N., Singh, V. P., and Asha, S. (2014). First report of Cephaliophora irregularis associated with the deterioration of Jatropha curcas L. seeds. J. Mycopathol. Res. 52, 153-154.

Vecstaudza, D., Grantina-Ievina, L., Makarenkova, G., Kasparinskis, R., Selga, T., Steinberga, V., et al. (2018). The impact of wood-derived biochar on the survival of Trichoderma spp. and growth of Secale cereale L. in sandy soil. Biocontrol. Sci. Technol. 28, 341-358. doi: 10.1080/09583157.2018.1450488

Wang, G., Govinden, R., Chenia, H. Y., Ma, Y., and Ren, G. (2019). Suppression of Phytophthora blight of pepper by biochar amendment is associated with improved soil bacterial properties. Biol. Fert. Soils 55, 813-824. doi: 10.1007/ s00374-019-01391-6

Wang, G., Ma, Y., Guo, D., Cao, Y., Luo, D., Zhao, J., et al. (2017). Applicationrate-dependent effects of straw biochar on control of Phytophthora blight of chilli pepper and soil properties. Acta. Pedol. Sin. 54, 204-215. doi: 10.11766/ trxb201604140027

Wang, Q., Ma, Y., Yang, H., and Chang, Z. (2014). Effect of biofumigation and chemical fumigation on soil microbial community structure and control of pepper Phytophthora blight. World J. Microbiol. Biotechnol. 30, 507-518. doi: 10.1007/s11274-013-1462-6
Widmer, T. L. (2014). Screening Trichoderma species for biological control activity against Phytophthora ramorum in soil. Biol. Control 79, 43-48. doi: 10.1016/j. biocontrol.2014.08.003

Wu, H., Qin, X., Wu, H., Li, F., Wu, J., Zheng, L., et al. (2020). Biochar mediates microbial communities and their metabolic characteristics under continuous monoculture. Chemosphere 246:125835. doi: 10.1016/j.chemosphere.2020. 125835

Xie, Z., Xu, Y., Liu, G., Liu, Q., Zhu, J., Tu, C., et al. (2013). Impact of biochar application on nitrogen nutrition of rice, greenhouse-gas emissions and soil organic carbon dynamics in two paddy soils of China. Plant Soil 370, 527-540. doi: $10.1007 / \mathrm{s} 11104-013-1636-\mathrm{x}$

Yao, Q., Liu, J., Yu, Z., Li, Y., Jin, J., Liu, X., et al. (2017). Three years of biochar amendment alters soil physiochemical properties and fungal community composition in a black soil of northeast China. Soil Biol. Biochem. 110, 56-67. doi: 10.1016/j.soilbio.2017.03.005

Zhang, C., Lin, Y., Tian, X., Xu, Q., Chen, Z., and Lin, W. (2017). Tobacco bacterial wilt suppression with biochar soil addition associates to improved soil physiochemical properties and increased rhizosphere bacteria abundance. Appl. Soil Ecol. 112, 90-96. doi: 10.1016/j.apsoil.2016. 12.005

Zhang, M., Riaz, M., Zhang, L., Xia, H., El-Desouki, Z., and Jiang, C. (2019). Response of fungal communities in different soils to biochar and chemical fertilizers under simulated rainfall conditions. Sci. Total. Environ. 691, 654-663. doi: 10.1016/j.scitotenv.2019.07.151

Zheng, Y., Xue, Q., Xu, L., Xu, Q., Lu, S., Gu, C., et al. (2011). A screening strategy of fungal biocontrol agents towards Verticillium wilt of cotton. Biol. Control 56, 209-216. doi: 10.1016/j.biocontrol.2010. 11.010

Conflict of Interest: The authors declare that the research was conducted in the absence of any commercial or financial relationships that could be construed as a potential conflict of interest.

Copyright (C) 2020 Wang, Ma, Chenia, Govinden, Luo and Ren. This is an open-access article distributed under the terms of the Creative Commons Attribution License (CC BY). The use, distribution or reproduction in other forums is permitted, provided the original author(s) and the copyright owner(s) are credited and that the original publication in this journal is cited, in accordance with accepted academic practice. No use, distribution or reproduction is permitted which does not comply with these terms. 